\title{
Keefektifan Model Problem Based Learning Berbantu Media Audio Visual Terhadap Kedisiplinan Siswa
}

\author{
Harland Paningga ${ }^{1}$, Ikha Listyarini ${ }^{2}$, Choirul Huda ${ }^{3}$ \\ 1,2,3 Pendidikan Guru Sekolah Dasar, Fakultas IImu Pendidikan, Universitas PGRI Semarang \\ e-mail: paningga14@gmail.com
}

\begin{abstract}
ABSTRAK
Peneliti ini bertujuan untuk mengidentifikasi efektif atau tidaknya model pembelajaran Keefektifan model problem based learning berbantu media audio visual terhadap kedisiplinan siswa kelas V SD Negeri Sawanga. Jenis penelitian ini adalah Kuantitatif dengan desain True Eksperimental yaitu Pretest-Posttest Control Group Desaign. Populasi dalam penelitian ini adalah siswa kelas V, Sampel yang diambil adalah 11 Siswa sebagai kelompok eksperimen, dan 11 siswa sebagai kelompok kontrol, dengan menggunakan teknik Simple random sampling. Nilai kedisiplinan diperoleh dari nilai pretest dan posttest. Hasil penelitian ini diperoleh dengan melakukan analisis data awal, uji normalitas dengan uji lilliefors, uji homogenitas, dan analisis data akhir dengan uji T-test. Berdasarkan pada analisis data akhir yang telah dilakukan perhitungan uji T-test diperoleh thitung > ttabel yaitu 4,990 > 1,725 maka hipotesis dapat diterima, dan dengan demikian dapat disimpulkan bahwa pembelajaran dengan model problem based learning berbantu media audio visual efektif terhadap kedisiplinan siswa kelas V SD Negeri Sawangan". Bedasarkan hasil penelitian ini saran yang dapat disampaikan adalah supaya model pembelajaran problem based learning berbantu media audio visual dapat digunakan sebagai alternative guru dalam mengaajar.
\end{abstract}

Kata kunci: model pembelajaran Problem Based Learning, media Audio Visual,Kedisiplinan

\begin{abstract}
This researcher aims to identify whether or not the learning model is effective The effectiveness of the problem-based learning model assisted by the audio visual media towards the discipline of fifth grade students of SD Negeri Sawangan. This type of research is Quantitative with True Experimental design, namely the Pretest-Posttest Desaign Control Group. The population in this study were grade V students. The samples taken were 11 students as the experimental group, and 11 students as the control group, using the Simple random sampling technique. The value of discipline is obtained from the value of the pretest and posttest. The results of this study were obtained by conducting preliminary data analysis, normality test with lilliefors test, homogenitas and final data analysis with T-test. Based on the final data analysis that has been calculated T-test test obtained tcount> ttable which is 4.990> 1.725 , the hypothesis can be accepted, and thus it can be concluded that learning with problem based learning models assisted audio visual media is effective against the discipline of fifth grade elementary school students Sawangan ". Based on the results of this study, the suggestion that can be conveyed is that the learning model of problem-based learning assisted by audio-visual media can be used as an alternative teacher in teaching
\end{abstract}

Keywords : Problem Based Learning learning model, Audio Visual media, Discipline

\section{Pendahuluan}

Indonesian Journal Of Educational Research and Review | 110 
Bangsa yang maju adalah bangsa yang sumber daya manusianya berkualitas tinggi. Adapun cara agar suatu bangsa memiliki sumber daya manusia yang berkualitas tinggi yaitu dengan pendidikan. Pendidikan merupakan sebuah proses mencetak generasi penerus bangsa. Dalam UU Nomor 20 tahun 2003 dijelaskan, "Pendidikan adalah usaha sadar dan terencana untuk mewujudkan suasana belajar dan proses pembelajaran peserta didik secara aktif mengembangkan potensi dirinya untuk memiliki kekuatan spiritual keagamaan pengendalian diri, kepribadian, akhlak yang mulia, serta keterampilan yang diperlukan dirinya, masyarakat, bangsa dan negara".

Penjelasan di atas menyebutkan bahwa pendidikan merupakan usaha sadar dan terencana. Maka dapat diartikan bahwa pendidikan itu tidak terjadi secara kebetulan saja atau asal-asalan yang justru akan menurunkan kualitas sumber daya manusia suatu bangsa, tetapi pendidikan adalah usaha sadar dan terencana dari pendidik. Oleh karenanya pendidikan merupakan faktor yang sangat penting dalam memajukan kualitas suatu bangsa. Melalui pendidikan yang berkualitas dapat mengembangkan sumber daya manusia yang baik, dan mampu berpikir kritis, kreatif, produktif serta disiplin tinggi.

Kaitannya dalam suatu proses pendidikan jika di dalamnya terdapat suatu hambatan maka resikonya adalah sulit terciptanya suatu sumber daya manusia yang berkualitas. Oleh karenanya diperlukan proses pembelajaran yang benar-benar terusaha dan terencana guna membentuk sebuah disiplin ilmu pada individu, sebagai penerus generasi bangsa dan sebagai dasar pembentukan individu yang berpengetahuan dan berkarakter tinggi di masa sekarang dan akan datang. Upaya untuk mendukung meningkatnya nilai karakter generasi sekarang dan generasi mendatang, baru-baru ini pemerintah telah mengeluarkan program Penguatan Pendidikan Karakter (PPK), dimana karakter menjadi poin utama dalam meningkatkan sumber daya manusia. Yang mana bukan hanya intelektualnya saja yang harus kuat tetapi juga dilengkapi dengan karakternya yang kuat. Seperti yang sudah tertulis pada Peraturan Presiden Republik Indonesia Nomor 87 tahun 2017 Pasal 3 tentang Penguatan Pendidikan Karakter, yang berbunyi sebagai berikut :

"Penguatan Pendidikan Karakter (PPK) dilaksanakan dengan menerapkan nilai-nilai Pancasila dalam Pendidikan karakterter utama meiliputi nilai-nilai religius, jujur, toleran, disiplin, bekerjakeras, kreatif, mandiri, demokratis, rasa ingin tahu, semangat kebangsaan, cinta tanah air, menghargai prestasi, komunikatif, cinta damai, gemar membaca, peduli lingkungan peduli sosial, dan bertanggung jawab".

Sekolah merupakan lembaga yang dipercaya masyarakat dalam pendidikan nomor dua setelah keluarga. Dengan adanya program Penguatan Pendidikan Karakter di sekolah diharapkan sekolah dapat meningkatkan pengajaran pengetahuan, norma dan karakter terhadap peserta didik. Salah satu nilai karakter yang di ajarkan di sekolah adalah nilai kedisiplinan. Setiap siswa di harapkan memiliki kedisiplinan. Dengan dibekali dengan kedisiplinan siswa dapat memimpin dirinya agar dapat mengontrol segala apa yang dilakukan. Disiplin di sekolah adalah proses peserta didik untuk dapat bersikap taat pada kegiatan dan peraturan yang ada di sekolah, karena pada dasarnya tata tertib dan aturan yang ada di sekolah dapat memberikan dampak yang baik bagi pertumbuhan kepribadian siswa.

Adapun masalah utama disiplin di sekolah adalah perilaku peserta didik, yang cendrung berakibat pada kurang efektifnya kegiatan pembelajaran. Berdasarkan pada hasil wawancara pada guru kelas V di SD Negeri Sawangan peneliti mendapatkan informasi berbagai masalah yang menunjukkan bahwa siswa mempunyai masalah yang berhubungan dengan kedisiplinan antara lain : perilaku siswa sering terlambat hadir di sekolah, perilaku siswa sering mencontek saat ulangan, menyalahi aturan berpakaian yang sudah ditetapkan dalam peraturan sekolah, menggangu siswa lain di kelas saat pembelajaran, dan kurang memperhatikan saat pembelajaran.

Hasil observasi di kelas V SD Negeri Sawangan, pada tanggal 27 November 2018 menunjukan hasil data kehadiran siswa di bulan September terdapat 11 siswa tidak hadir lebih dari $20 \%$ dalam satu bulan, hal tersebut tentu telah melanggar tata tertib sekolah seperti yang tercantum dalam peraturan tata tertib SD Negeri Sawangan nomor 3 yaitu : (1) 
Siswa absen hanya apabila benar benar sakit atau karna ada kepentingan sangat penting / tidak bisa di wakilkan (2) Urusan siswa di kerjakan diluar sekolah atau waktu libur sehingga tidak mengganggu kegiatan sekolah.

Berdasarkan uraian masalah yang ada di SD Negeri Sawangan di atas, maka tentunya perlu diberikan tindakan penanganan yang tepat agar masalah berkaitan dengan kedisiplinan tersebut tidak membesar dan membudaya di kalangan siswa, dan pada akhirnya akan menjadi kerugian bagi siswa sendiri baik dalam lingkungan sekolah, keluarga maupun lingkungan masyarakat.

Usaha sadar dan terencana dalam membantu meningkatkan kedisiplinan siswa, dapat dilakukan dengan memberikan pengajaran di kelas dengan menggunakan model problem based learning atau biasa disebut pembelajaran berbasis masalah. Menurut Fathurrohman (2017: 112) "Model Pembelajaran problem based learning adalah pembelajaran yang menggunakan masalah nyata (autentik) yang tidak terstruktur (illstructured) dan bersifat terbuka sebagai konteks peserta didik untuk mengembangkan keterampilan menyelesaikan masalah dan berfikir kritis sekaligus membangun pengetahuan baru".

Peneliti memilih model problem based learning karena model tersebut sesuai dengan permasalahan yang dialami siswa. Model problem based learning berbasis pada pemecahan masalah, dengan memberikan permasalahan yang ada di kehidupan nyata sebagai sebuah konteks untuk para siswa dapat berlatih tentang bagaimana cara berpikir cerdas dan kritis, serta dapat belajar memahami sebuah permasalahan dan menganalisis bagaimana cara menyelesaikan permasalahan tersebut dengan tepat. Peneliti memilih model ini dikarenakan model problem based learning masih jarang digunakan, salah satunya di SD Negeri Sawangan yang belum menggunakan model tersebut.

Salah satu media yang sesuai digunakan untuk penyampaian materi dengan model pembelajaran problem based learning adalah media audio visual karena media ini dapat di gunakan dan disesuaikan dengan tingkat kemampuan siswa. Dengan menggunakan media audio visual akan lebih menarik perhatian siswa dalam pembelajaran, media audio visual juga dapat menumbuhkan motivasi siswa, materi akan lebih jelas maknanya sehingga dapat lebih mudah di pahami siswa, pengajaran juga tidak monoton pada komunikasi verbal melalui penuturan kata kata oleh guru, tetapi siswa juga dapat melakukan pengamatan, sehingga pembelajaran akan terasa lebih inovatif dan tidak membosankan.

Dengan diterapkannya model problem based learning dan media audio visual, diharapkan siswa dapat lebih mudah memahami dan menguasai kemampuan tertentu melalui kegiatan pembelajaran serta dapat mengatasi masalah yang di alami. Berdasarkan latar belakang di atas maka peneliti mengambil judul "Keefektifan model problem based learning berbantu media audio visual terhadap kedisiplinan siswa kelas V SD Negeri Sawangan".

\section{Metode}

Pelaksanaan kegiatan penelitian pembelajaran dilaksanakan pada semester II di SD Negeri Sawangan Pekalongan. Metode penelitian yang digunakan peneliti pada penelitian ini yaitu kuantitatif dan jenis penilitian true eksperimental design dengan bentuk pretest-postest control group design. Dalam rancangan penelitian ini meliputi dua kelompok dari populasi yang dipilih secara Simple random sampling, kemudian diberi pretest untuk mengetahui keadaaan awal adalah perbedaan antara kelompok eksperimen dan kelompok kontrol (Sugiyono, 2016: 112). Desain dari penelitian ini dapat dilihat pada gambar 1.

\begin{tabular}{|cccc|}
$R$ & 01 & $X$ & 02 \\
$R$ & 03 & & 04 \\
\hline
\end{tabular}




\section{Gambar 1. Desain Pretest-Posttest Control Group Design}

Teknik pengumpulan data yang digunakan dalam penelitian ini yaitu tes. Instrumen menggunakan tes (Pretest-Posttest) berupa angket kedisiplinan. Menurut Arikunto (2010: 194) Kuesioner adalah Sejumlah pertanyaan tertulis yang digunakan untuk memperoleh informasi dari responden dalam arti laporan tentang pribadinya, atau hal-hal yang diketahui. Angket dalam penelitian ini berisi pernyataan positif dan negatif, ada empat pilihan jawaban yaitu Sangat Setuju (SS), Setuju (S), Tidak Setuju (TS), Sangat Tidak Setuju (STS).

Uji analisis data dalam penelitian ini menggunakan: 1) uji normalitas untuk mengetahui sampel dari populasi berdistribusi normal atau tidak (Sudjana, 2005: 466), 2) uji homogenitas dilakukan untuk memastikan apakah asumsi homogenitas pada masing-masing kategori sudah terpenuhi atau belum, 3) uji hipotesis dapat dilakukan setelah diketahui hasil pretest dan posttest. Untuk mengujinya peneliti menggunakan $t$-test untuk mengetahui perbedaan hasil pada dua kelompok antara yang diberi perlakuan dengan yang tidak diberi perlakuan (Soegeng dan suharno, 2010: 62).

\section{Hasil dan Pembahasan}

Peneliti mengambil judul "Keefektifan Model Problem Based Learning Berbantu Media Audio visual Terhadap Kedisiplinan Siswa" dengan tujuan meningkatkan kedisiplinan siswa kelas V di SD Negeri Sawangan. Data awal berupa hasil Pretest antara kelompok eksperimen dan kelompok kontrol menunjukkan bahwa tidak ada perbedaan yang signifikan antara kelompok eksperimen dengan kelompok kontrol. Rata-rata nilai pretest kedisiplinan siswa kelas $\mathrm{V}$ pada kelompok eksperimen sebesar 65,72 sedangkan pada kelompok kontrol sebesar 67,09. Selanjutnya peneliti memberikan perlakuan berupa model pembelajaran problem based learning berbantu media audio visual kepada kelompok eksperimen.

Setelah diberikannya perlakuan, peneliti melakukan posttest yang mana hasilnya terdapat perubahan tingkat kedisiplinan siswa. Kelompok eksperimen pada saat Preetest memiliki hasil rata-rata 65,72 setelah diberikannya perlakuan menjadi 81,36 , yang berarti terjadi peningkatan sebesar 15,64. Sedangkan pada kelompok kontrol rata-rata hasil Pretest sebesar 67,09 dan Posttest memiliki hasil rata-rata sebesar 67,45, yang artinya terjadi peningkatan meski tidak signifikan sebesar 0,36. Berdasarkan analisis tersebut maka dapat dikatakan ada perbedaan antara kelompok kontrol dan kelompok eksperimen yang telah diberi perlakuan dengan model pembelajaran problem based learning berbantu media audio visual, untuk lebih jelasnya dapaat dilihat pada gambaar 2 . 
Gambar 2 Hasil Pretest dan Posttest kelompok Kontrol dan Eksperimen

Berdasarkan Gambar 2 di atas dapat diketahui bahwa hasil pretest dan posttest menunjukkan bahwa terdapat peningkatan antara pretest yang sebelum diberikan perlakuan dengan nilai posttest yang sudah diberikan perlakuan dengan model problem based learning berbantu media audio visual, Setelah mendapatkan data hasil pretest dan posttest Selanjutnya dilakukan pengujian data dengan uji normalitas yang dapat dilihat pada tabel 1 dan 2.

Tabel 1. Uji Normalitas Awal

\begin{tabular}{cccc}
\hline Kelompok & $\mathrm{L}_{\text {tabel }}$ & $\mathrm{L}_{0}$ & Keterangan \\
\hline Eksperimen & 0,249 & 0,154 & Normal \\
Kontrol & 0,249 & 0,207 & Normal \\
\hline
\end{tabular}

Tabel 2. Uji Normalitas Akhir

\begin{tabular}{cccc}
\hline Kelompok & $\mathrm{L}_{\text {tabel }}$ & $\mathrm{L}_{0}$ & Keterangan \\
\hline Eksperimen & 0,294 & 0,177 & Normal \\
Kontrol & 0,294 & 0,176 & Normal \\
\hline
\end{tabular}

Kelompok eksperimen dengan $\mathrm{N}=11$ dan taraf signifikan $5 \%$, dari hasil perhitungan didapatkan hasil $\mathrm{L}_{0}<\mathrm{L}_{\text {tabel }}$, Berdasarkan uji normalitas di atas dapat diambil kesimpulan bahwa data yang diperoleh setelah melakukan uji normalitas awal dan akhir merupakan data yang berdistribusi normal. Langkah selanjutnya adalah melakukan uji homogennitas, adapun hasilnya dapat dilihat pada Tabel 3 dan 4.

Tabel 3. Uji Homogenitas Awal

\begin{tabular}{cccc}
\hline Sampel & $\mathrm{F}_{\text {hitung }}$ & $\mathrm{F}_{\text {tabel }}$ & Keterangan \\
\hline Eksperimen & 2,15 & 2,97 & Homogen \\
Kontrol & 2,15 & 2,97 & Homogen \\
\hline
\end{tabular}

Tabel 4. Uji Homogenitas Akhir

\begin{tabular}{cccc}
\hline Sampel & $\mathrm{F}_{\text {hitung }}$ & $\mathrm{F}_{\text {tabel }}$ & Keterangan \\
\hline Eksperimen & 2,15 & 2,97 & Homogen \\
Kontrol & 2,15 & 2,97 & Homogen \\
\hline
\end{tabular}


Karena $\mathrm{F}_{\text {hitung }}<\mathrm{F}_{\text {tabel }}$, maka dapat di simpulkan sampel Uji homogenitas awal dan akhir berasal dari populasi yang homogen. Langkah selanjutnya adalah menguji hipotesis dengan t-test.

Dari perhitungan t-test diperoleh $\mathrm{t}_{\text {hitung }}=4,990$. Selanjutnya dikonsultasikan dengan tabel dengan $\mathrm{db}=\left(\mathrm{N}_{1}+\mathrm{N}_{2}\right)-2=(11+11)-2=20$ dan taraf signifikansi $5 \%$ diketahui $t_{\text {tabel }}=2,086$ sehingga $t_{\text {hitung }}>t_{\text {tabel }}$ yaitu 4,990 $>2,086$. Dengan demikian $\mathrm{H}_{\alpha}$ ditolak dan $\mathrm{H}_{\mathrm{a}}$ diterima. Oleh karena itu hipotesis yang berbunyi "Model problem based learning berbantu media audio visual efektif dalam meningkatkan kedisiplinan siswa kelas V SD Negeri Sawangan" diterima kebenarannya.

Hasil tersebut sejalan dengan penelitian yang dilakukan Afifudin (2017: 246) didapatkkan hasil pencapaian karakter disiplin siswa secara klasikal, pada materi pertumbuhan dan perkembangan melalui model pembelajaran problem based learning tergolong baik dengan persentase capaian $82,5 \%$. Berdasarkan Penelitian tersebut dapat disimpulkan bahwa pembelajaran menggunakan model problem based learning berbantu media audio visual dapat meningkatkan kedisiplinan siswa.

\section{Simpulan}

Berdasarkan analisis data hasil penelitian dan pembahasan, dapat disimpulkan bahwa model problem based learning berbantu media audio visual efektif terhadap kedisiplinan siswa kelas V SD Negeri Sawangan. Setelah melakukan penelitian dengan menggunakan model pembelajaran problem based learning berbantu media audio visual, terdapat peningkatan kedisiplinan siswa kelas V SD Negeri Sawangan. Dilihat berdasarkan hasil perhitungan analisis rumus t-test diperoleh hasil $t_{\text {hitung }}=4,990$. Selanjutnya dikonsultasikan dengan $\mathrm{t}_{\text {tabel }}$ dengan $\mathrm{db}=20$ dan taraf signifikansi $5 \%$ diketahui $\mathrm{t}_{\text {tabel }}=$ 2,086 sehingga $t_{\text {hitung }}>t_{\text {tabal }}$ yaitu 4,990 > 2,086. Dengan demikian $\mathrm{H}_{0}$ ditolak dan $\mathrm{H}_{\mathrm{a}}$ diterima. Oleh karena itu hipotesis yang berbunyi "Model problem based learning berbantu media audio visual efektif terhadap kedisiplinan siswa kelas V SD Negeri Sawangan".

\section{Daftar Pustaka}

Afifudin. 2017. "Karakter Disiplin dan percaya Diri Melalui Model Pembelajaran problem Based Learning Materi Pertumbuhan dan Perkembangan". Journal UNNES. Vol 6 No 2 Hal 240-247. https://journal.unnes.ac.id/sju/index.php/ujbe/article/view/19327. Diakses 14 Februari 2019.

Arikunto, Suharsimi. 2010. Prosedur Penelitian Suatu Pendekatan Praktik. Jakarta: Rineka Cipta

. 2012. Dasar-Dasar Evaluasi Pendidikan. Jakarta: Bumi Aksara.

Author (2009). Problem based learning and prospective teachers: Implications for problem solving and practice. Journal on Excellence in College Teaching, 20

Bilgin. I, Senocak. E, and Zozbilir. M. 2009. The Effects of Problem-Based Learning Instruction on University Students' Performance of Conceptual and Quantitative Problems in Gas Concepts. EURASIA Journal of Mathematics, Science and Technology Education., vol 5 (2).

Djamarah, Syaiful bahri. 2006. Strategi Belajar Mengajar. Jakarta: PT Rineka cipta 
Fakhriyah, F. 2014. Penerapan Problem Based Learning Dalam Upaya Mengembangkan Kemampuan Berpikir Kritis Mahasiswa. Jurnal Pendidikan Ipa Indonesia, Jpii 3 (1) (2014) 95-101

Fathurohman, Muhammad. 2016. Model Model Pembelajaran Inovatif, Alternatif Desain Pembelajaran yang Menyenangkan. Malang: AR-RUZZ Media

Hamalik, Oemar. 2008. Kurikulum dan Pembelajaran. Jakarta: Bumi Aksara.

Hamdani, 2011. Strategi Belajar Mengajarr. Bandung: Pustaka Setia.

Hudoyo, H. 2008. Metode Teknik dan Strategi dalam Belajar. Bandung: Tarsito.

Jeong, H., \& Hmelo Silver, C. E. (2010). Productive use of learning resources in an online problem-based learning environment. Computers in Human Behavior, 26,

Peraturan Presiden Republik Indonesia Nomor 87 tahun 2017

Sanaki, H.A. 2011. Media Pembelajaran. Yogyakarta: Kaukuba.

Simone, Cristina De. 2014. Problem Based Learning in Teacher Education. International journal Humanities and social science Vol 4 No 12.

Sudarman. 2007. Problem Based Learniing: Model Pembelajaran untuk Mengembangkan dan Meningkatkan Kemampuan Memecahkan Masalah. Jurnal Pendidikan Inovatif. 2 (2): 68-73

Soegeng, A.Y, dan Suharno, Agus. 2010. Statistika Inferensial.Semarang: IKIP PGRI Semarang Press.

Sudjana, M.A. 2005. Metoda Statistika. Bandung : PT Tarsito

Sugiyono. 2017. Metode Penelitian Pendidikan Pendekatan Kuantitatif, Kualitatif, dan R\&D. Bandung: Alfabeta

Undang-Undang Nomor 20 Tahun 2003 tentang Sistem Pendidikan Nasional

Walker, A. \& Leary, H. 2009. A problem based learning meta analysis: differences across problem types, implementation types, disciplines, and assessment levels. Journal of Problem-based Learning, Vol. 3 No. 1, pp. 12-43.

Wulandari, Nadiah., Sjarkawi \& Damris M. 2011. Pengaruh Problem Based Learning dan Kemampuan Berpikir Kritis Terhadap Hasil Belajar Mahasiswa. Tekno-Pedagogi. 1(1). 14-24 